\title{
Protection of Health Workers, Patients and Facilities in Times of Violence - Report
}

A Conference Convened by the Center for Public Health and Human Rights Johns Hopkins Bloomberg School of Public Health

Bellagio, Italy, November 2013

\section{Introduction}

Attacks on and interferences with healthcare providers, facilities and transports pose a grave threat to availability of and access to healthcare during armed conflict and civil disturbances. We have witnessed repeated and systematic violations of universal norms requiring the respect for and protection of healthcare services, committed by state military and police forces as well by armed groups. In some cases health workers, ambulances and facilities are specifically targeted; in other cases they are the result of more generalized assaults on civilian populations. Aside from violent attacks, states and armed groups engage in conduct such as occupying health facilities, obstructing travel through checkpoints and placing military posts near clinics, limiting access. Further, states fail to provide security for health workers providing treatment or preventive services, such as vaccinations.

In recent years, the humanitarian, human rights, health professional and global health communities have begun to take proactive steps to address the problem. Actions have included efforts to strengthen norms of respect for and protection of health, to broaden data collection to gain a better understanding of incidents and trends, to analyze events toward improving security and to strengthen accountability mechanisms. But knowledge gaps remain large, and the problem remains at the fringes of global health awareness. The Center for Public Health and Human Rights at the Johns Hopkins Bloomberg School of Public Health convened a diverse group of stakeholders at the Rockefeller Foundation's Bellagio Center to take stock of the current situation, to consider whether current initiatives can be better integrated or aligned, and to identify gaps in knowledge, protection, monitoring and accountability.

Conference participants were called upon to identify key actions by which the international community, including states, health ministries, United Nations (UN) agencies, non-governmental agencies (NGOs) and professional health organizations could reverse the erosion of norms for the respect for and protection of healthcare in times of armed conflict and other situations of violence, and identify potential areas for future research, in order to ensure action is grounded in a strong evidence base.

This report offers a review of the rich and varied discussions that took place during the course of the three-day conference that resulted in a Call for Action, including a global research agenda. 


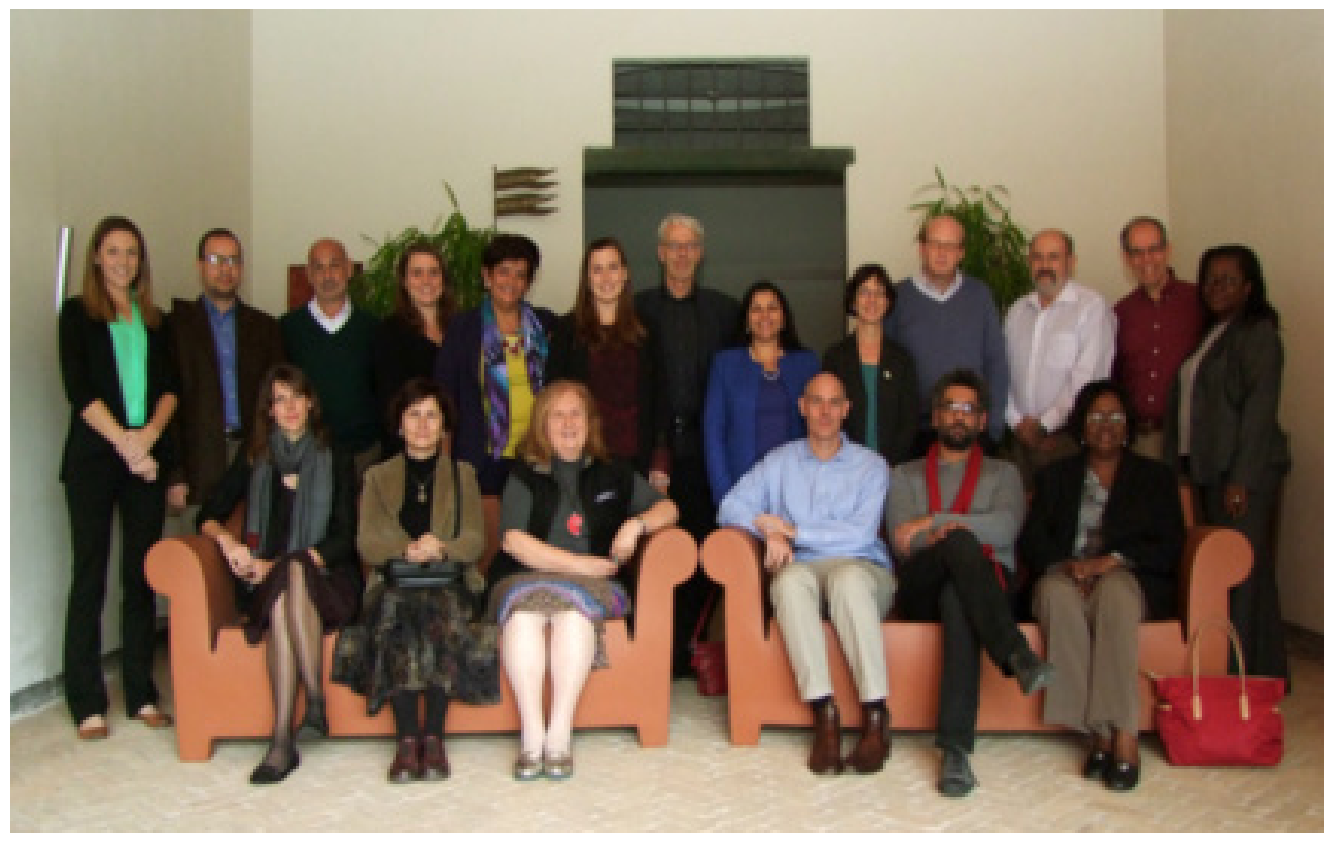

\section{Participants}

Naeema Hassan Al-Gasseer, Eastern Mediterranean Regional Office, World Health Organization Joseph Amon, Director, Health and Human Rights Division, Human Rights Watch

Cathrine Andersen, Counsellor, Humanitarian Affairs, Permanent Mission of Norway in Geneva

Emily Clouse, Senior Research Coordinator, Center for Public Health and Human Rights, Johns Hopkins Bloomberg School of Public Health Ran Cohen, Executive Director, Physicians for Human Rights - Israel

Lola Dare, CEO, Centre for Health Sciences Training, Research and Development

Laurent Dutodoir, Political Affairs Officer, Office of the Special Representative of the Secretary General for Children and Armed Conflict Katherine Footer, Research Associate, Center for Public Health and Human Rights, Johns Hopkins Bloomberg School of Public Health

Angela Gussing, Deputy Director of Operations, International Committee of the Red Cross

Barry Lowenkron, Vice President of International Programs, John D. and Catherine T. MacArthur Foundation

Caroline Moulins, Healthcare in Danger Project, International Committee of the Red Cross

Margaret Mungherera, President, World Medical Association

Enrico Pavignani, Independent public health consultant

Leonard Rubenstein, Director, Program on Human Rights, Health and Conflict, Center for Public Health and Human Rights,

Johns Hopkins Bloomberg School of Public Health

Zaher Sahloul, President, Syrian American Medical Society

Judith Shamian, President, International Council of Nurses

Susannah Sirkin, Director, International Policy and Engagement, Physicians for Human Rights

Egbert Sondorp, Hon. Senior Lecturer, London School of Hygiene and Tropical Medicine

Feride Aksu Tanik, Turkish Medical Association Office for International Relations

\section{The nature of the problem}

\section{Overview}

A review of attacks on and interference with health workers, facilities and patients over the past three decades reveals both the global scope of the problem and the wide variety of political contexts in which it exists. Assaults on health services have often been viewed as a problem unique to armed conflict, whether international or non-international in scope. Yet we know that assaults on health also take place during times of political turmoil or civil disturbances as well as in armed conflict. They occur in fragile or weak states and in strong ones, in very poor and in middle- and high-income countries. Violations of international law are committed by formal military forces, paramilitary groups, police and armed groups. Victims include patients, doctors, nurses, ambulance drivers and attendants, and community health workers including vaccinators.

Violations against health workers and patients include harassment, beatings, torture, killings, disappearance, detention and 
prosecution, as well as more insidious threats and obstructions to healthcare access. In some cases, state prosecutors have brought formal charges in courts against health workers for acting in accordance with their duty to provide impartial medical care. Facilities have been shelled, tear-gassed, looted and occupied either for military purposes or to control access to care. In some cases, medical records or other confidential information has been demanded in order to identify individuals who may be political opponents of the perpetrators. Ambulances have been fired upon and their access across checkpoints has been unreasonably delayed or prevented entirely.

Some states have enacted or stepped up enforcement of laws that either explicitly deem the impartial provision of healthcare to a person deemed to be associated with a terrorist organization to be a crime, or apply general anti-terror laws to the provision of medical care. In other states, doctors and nurses providing healthcare for victims of human rights violations are individually targeted for either speaking out or openly providing care to victims.

Aside from these direct attacks, there are many circumstances, though little documented, where states fail to live up to their responsibilities to provide protection to health workers or ensure continued access to healthcare during periods of insecurity. Passivity in the face of obligations to assure access to health services equally violates international law.

There is evidence that direct assaults, disruption in supply chains, deterioration of infrastructure and shorter working hours are profoundly disruptive to access to care. Health worker vulnerability has led to outward migration of qualified staff, high turnover of managers and diminished access to care. Less visible effects can include proliferation of agencies that seek to fill gaps in services during periods of pervasive violence, but often lack the coordination and continuity necessary to ensure quality of services is maintained. Further, understandable concerns for aid
2013 was a brutal year for attacks on health and in many different contexts. In Syria, government forces assaulted health workers and facilities as a matter of systematic policy. Two thirds of hospitals have been shelled, mostly by government forces, and a third of them destroyed. Hundreds of health workers have been killed and imprisoned. Thousands of health professionals in Syria have fled. Availability of clean water and sanitation has been severely compromised. Polio has returned to the country.

In response to violent attacks on political demonstrators, doctors in Turkey provided emergency medical services. The government required physicians to report whom they treated and charged medical groups with opposing the government and is now seeking to criminalize unauthorized medical care. Physicians were required to report whom they treated and charged medical groups with opposing the government, and is now seeking to criminalize unauthorized medical care.

In Pakistan and Nigeria, 30 community health workers vaccinating children against polio have been murdered.

worker security have led, in some circumstances, to practices such as remote management using standardized practices without attention to context, militarization of healthcare and distancing from communities all of which can compromise quality. These disruptions in turn can create patients' fear of and distrust in the health system. We know less about the impact of pervasive interference on health services and health outcomes, though some studies have shown increases in maternal mortality and decreases in access to anti-retroviral drugs for treatment of HIV/AIDS, as well as severe disruptions in the treatment of other chronic diseases. Far more knowledge is needed to understand these outcomes, including effects on the health status of the population. Finally, health reconstruction in the wake of conflict is more complex and expensive in circumstances where infrastructure has been damaged or destroyed and human resources have been diminished by health worker flight.

It is not entirely clear whether strong and universal norms of respect and protection for healthcare have eroded, or whether norms 
Figure 1.

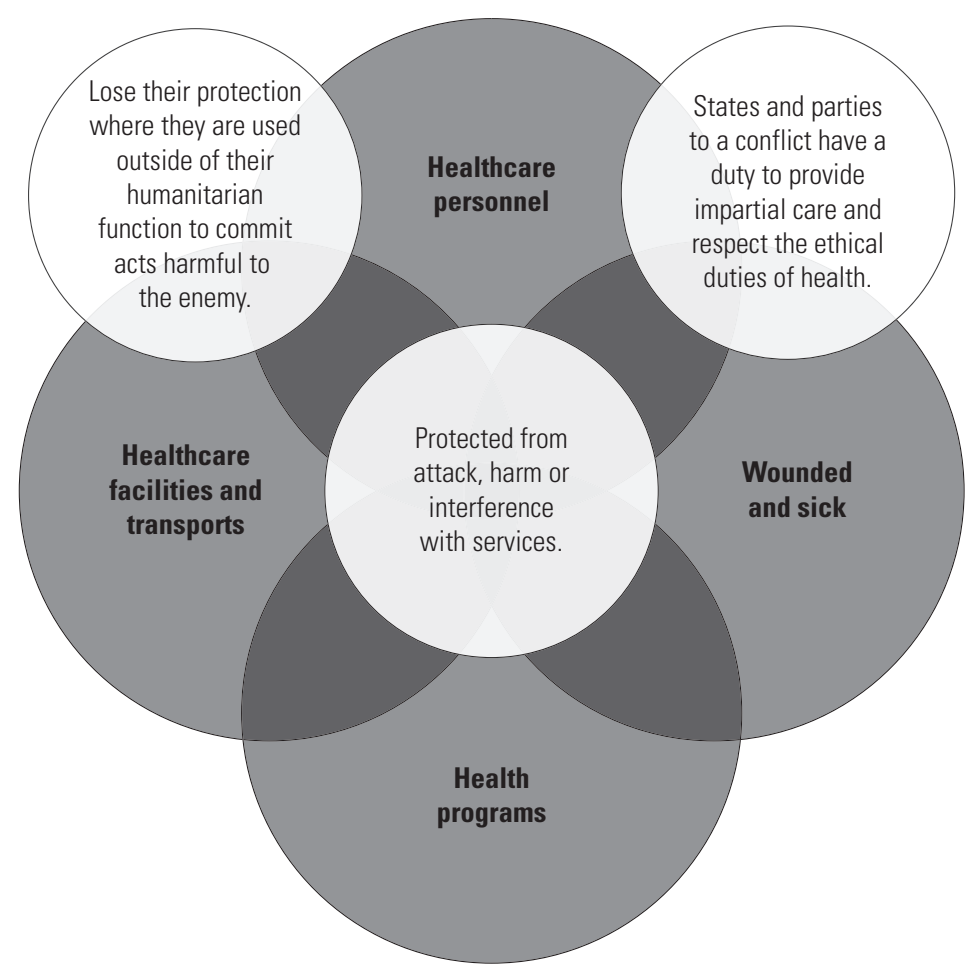

have been insufficiently upheld over the course of history. But those norms established under international law are powerful, as illustrated in this Venn diagram:

\section{Gaps in knowledge}

Despite the severity and impacts of assaults on health services, there exist serious gaps in our knowledge about the phenomenon.

These fall into three categories: routine data collection, research and awareness.

Routine data collection. In other realms of civilian protection, data collection and surveillance have profoundly informed and influenced responses at the global and national level, such as in campaigns to end the use of child soldiers and to ban anti-personnel landmines. Action to assess adherence to norms has been weak, though recent initiatives warrant development and support. The World Health Organization (WHO) and the UN Special Representative on Children in Armed Conflict are charged with developing more systematic methods for incident reporting. The WHO is required to provide global leadership in developing methods for collection and dissemination of data on attacks on health workers, facilities, ambulances and patients in complex emergencies. The Special Representative reports to the Security Council on specific incidents involving attacks on schools and hospitals, and is also authorized to require action plans and a monitoring and reporting mechanism for persistent violators. These initiatives need to be fully implemented and accompanied by others at the global, regional and national level to understand both general trends and the contextual factors that often determine the nature and impact of attacks. States, especially ministries of health, have a responsibility to develop incident reporting plans as well as to support independent monitoring from other sources including the High Commissioner for Human Rights. As we discuss later, civil society organizations also have a key role to play in the process. In reporting and monitoring, the goal should not be a single and integrated system. Rather, redundancy of effort is preferable to one integrated system, given different mandates and contexts in which violations take place. 
Research. In addition to insufficiencies in incident reporting, monitoring and data collection, there is a paucity of scientific studies needed to understand motivations of perpetrators, contextual factors driving attacks, and the impacts of attacks on healthworker migration, access to services, health infrastructure, health systems and health outcomes. Strategies for protection and security are insufficiently evaluated, so we lack knowledge of the most effective strategies for the protection of patients and the health workforce, including infrastructure, supplies and services during periods of social disruption. As a result it is difficult to draw lessons from one context that may be applicable to another context, or even in the same one.

Awareness of health worker rights and responsibilities. Increasing knowledge involves more than data and research. Health workers themselves often lack awareness of their rights to practice care impartially without state or other interference, and sometimes their experiences leave them with low expectations of protection. In certain cases, health workers don't recognize violations when they occur, or if they do they lack resources to know where or how to report them. These factors lead to feelings of disempowerment, leaving health workers vulnerable to pressure from states and armed groups to act unethically.

\section{Toward protection and accountability}

In recent years, the humanitarian community has intensively addressed means for increasing the security of their operations. The International Committee of the Red Cross's (ICRC) Healthcare in Danger project is building on these efforts to develop pragmatic means for increasing protection through a set of activities designed to engage key actors, including militaries, hospital and ambulance providers, health professional associations and armed groups. For example, in the realm of military practice, ICRC is addressing concerns such as inspection and passage practices at checkpoints, search operations in health facilities and fighting in proximity to health facilities. For facilities and ambulances, it is identifying practices that could offer greater safety, such as training and security procedures. ICRC is also convening states to consider expanding protection for healthcare services under national law.

UN agencies, including the Office for the Coordination of Humanitarian Affairs, have become more engaged, partnering with local health providers, leaders, ministries and others to advance protection through information sharing and coordinated responses. For some $\mathrm{UN}$ agencies the task is often complicated by tensions stemming from the need to work through national authorities whose forces may be the perpetrator. In some cases these relationships prevent agencies from providing humanitarian relief across borders, thus raising questions about fulfillment of their responsibilities. Further, in the past the need to work with member states frequently affected the willingness of the WHO, the UN Office for

\footnotetext{
There is no single pathway or means to achieve protection. Multiple human rights mechanisms and protection strategies can be reinforcing. Working independently, the ICRC, an investigatory commission of the UN Human Rights Council, Israeli and global human rights organizations, and the Special Representative on Children in Armed Conflict all contributed to major change in conduct of the Israeli Defense Forces regarding health facilities after the 2009 military operation by the Israeli Defense Forces in Gaza. Local civil society organizations demanded a transparent investigation and human rights organizations and the UN commission documented serious violations, resulting in visible public debate and pressure on the IDF to alter its conduct. Independently, the ICRC privately engaged with the Israeli military about incidents of concern and the Special Representative on Children in Armed Conflict received reports by both sides and conducted its own fact-finding, resulting in regular reports to the Security Council. These combined efforts bore fruit when, in the next episode of fighting in Gaza, there was significantly less damage to hospitals and interference with ambulances.
} 
the Coordinator of Humanitarian Affairs (OCHA), UNICEF and other agencies to speak out publicly about harm deliberately inflicted by member states on health workers and facilities. In the past two years, however, the WHO, UNICEF and OCHA have been more outspoken in their criticism of states and armed groups that perpetrate attacks.

At the same time, the full burden of assuring respect for and protection of health should not be placed on humanitarian organizations. Humanitarian response cannot solve the political problems that underlie a humanitarian crisis. Additionally, humanitarians are often constrained in what they can report because of the need to maintain access.

Protection responsibilities need to extend in the first instance to ministries of health. All too often these ministries have either failed to come to the defense of health workers and patients or, in some cases, actively participated with state security officials in undermining professional independence. Even in circumstances in which ministries are politically free to monitor and report, they frequently lack the knowledge, mandate or will to collect data or use their influence within the government to protect health workers.

Finally, accountability in the form of costs and consequences for those who commit violations is a key but undeveloped strategy to deter violators. Accountability needs to take place at a number of levels. There is increasing recognition that diplomatic action can and should be invoked to protect health in conflict. Tools are available through both bilateral and multilateral action and can include high-level meetings and special sessions of the UN General Assembly. Any international responses need to be coordinated with advocacy and civil society groups working at the national level. The Responsibility to Protect, designed to stimulate international action to protect civilians, still holds promise but faces major challenges because of the political controversies it spawned as a result of the Iraq war and the Libya intervention.
Formal human rights mechanisms at the global level, designed to stop atrocities, have great potential but have been infrequently invoked. In the past, the problem of attacks on health was considered an issue of the law of armed conflict rather than human rights law. As evidenced by a recent report to the $\mathrm{UN}$ General Assembly by the UN Special Rapporteur on the Right to the Highest Attainable Standard of Health, there is increasing recognition that human rights law provides a powerful basis for protection and accountability. The law extends beyond noninterference with health services to obligations to assure continuity and access to services in volatile environments and to assure security from interference by third parties. These norms need to be reinforced at every level and at every opportunity, including in post-conflict planning.

There are, moreover, powerful linkages between diplomatic action and invocation of human rights machinery to bring pressures from other states to bear on offenders. Existing mechanisms include mandatory self-reporting by states on their own record (with possibilities for civil society shadow reports) through Universal Periodic Review, human rights treaty bodies, reports by the Special Rapporteur on the Right to Health, and field investigations by the High Commissioner for Human Rights. These can enable states and UN agencies to exert pressure on violators. The newest mechanism derives from the mandate of the Special Representative on Children in Armed Conflict. The Special Representative reports annually on 20 conflict situations and other situations of concern. Its mechanism has great potential because of its ability to name perpetrators before the UN Security Council and put monitoring and reporting into place for states and armed groups listed as persistent violators. Further, action plans for compliance are not subject to review by governments that offend.

The jurisdiction of the International Criminal Court (ICC) can and should be invoked. Under its governing statute, attacks 
on health facilities are war crimes. Demands for referral to the ICC, as well as to regional human rights tribunals, can have a potentially deterrent effect and be a focal point for civil society action to demand adherence to norms.

Indeed, all these and regional and national mechanisms provide a key entry point for civil society. They can invoke available tools strategically and provide opportunities to mobilize health workers and others to demand action against impunity through influence on official reports, shadow reports and use of the media.

None of these mechanisms constitute a "silver bullet" to address the problem. Nor do the existing initiatives need to be integrated to create a single system. The multiplicity of efforts, even if overlapping to some extent, can expand opportunities to highlight the problem, promote accountability and reinforce one another. The key is to align these efforts toward the overarching goal of safe and secure health services. For example, action at high levels of the UN can strengthen the hand of ministries of health to perform key datacollection activities and demand adherence to norms by state military and security agencies. To be successful, however, there needs to be greater commitment to employ the mechanisms discussed. Political analysis is also needed to determine which UN agency or government will have the most influence in a particular situation.

Finally, protection and accountability can only improve if the broader global health community takes ownership of the problem as a fundamental feature of health and human security. It is known that fragile and conflictaffected states lag behind more stable states in achievement of the health-related Millennium Development Goals. Global campaigns to strengthen human resources for health and promote universal healthcare, however, take little account of the need to address attacks on and interference with health. Opportunities should be taken to incorporate protection of healthcare in times of crisis into global policy agendas and activities such as monitoring under the global code of conduct on health-worker migration and creation of the post-2015 development agenda. Global institutions such as the World Bank can also use their power and influence to address this issue. Principles including empowerment and engagement of multiple sectors and stakeholders can all be brought to bear on the problem.

\section{Civil society engagement}

In the past generation civil society organizations have organized toward a ban on antipersonnel landmines, use of child soldiers and other profound harms to civilians in conflict. Until recently, however, the leading proponents of protection of healthcare in conflict have been largely limited to humanitarian aid groups and a handful of human rights organizations. The leading edge of advocacy must now come from health workers, health advocacy and other civil organizations.

\section{Civil Society Engagement Activities}

- National health professional associations develop ethical standards on impartial care and protection of rights

- Incorporate training on impartial care and protection of rights in health professional training curriculum and in-service training

- Advocate for recognition of duties of impartiality and rights to protection in national laws

- Engage with governments to protect impartial care, and to monitor attacks and interference

- Liaise with UN agencies present in conflictaffected countries on monitoring, reporting and accountability

- Facilitate medical relief where needed

- Support and speak up on behalf of health workers

- Document and report violations

- Share experiences

- Raise public awareness 
Global medical and nursing organizations have in recent years engaged in more robust condemnation of attacks on healthcare at the global level, partnered with the WHO and ICRC's Healthcare in Danger project and joined international coalitions such as Safeguarding Health in Conflict. There is potential for more intensive engagement through educating national associations about the rights and responsibilities of health workers in conflict situations, assuring that protection of health is included in global health agendas and addressing the role of conflict in health-worker migration.

At the national level, the challenges are greater because of lower awareness of provider rights and responsibilities, as well as limited capacity by professional associations to set standards and influence governments in conflict-affected states. In many circumstances, the key is to strengthen national-level health professional organizations, enabling them to offer training in protection and impartiality, set standards, collect data and become more engaged at the national level. This can be done through regional and global cooperation, which can provide forums for technical assistance and a means of amplifying local voices.

When they are under assault, health professional groups, like civilians generally, are severely tested. National professional organizations can experience push back or worse for speaking against the practices of government security forces. For more than 20 years the Turkish Medical Association has been subjected to harsh criticism and even arrest of its members for standing up for profession-

alism, service to all in need and preservation of patient confidentiality. In some circumstances, faith-based groups may have the greatest space to speak out.

In Syria, in response to the assaults on health workers, patients and facilities, civil society has been at the forefront of documentation and advocacy. Even as they treat patients in dire conditions, local medical groups have organized to transmit information on attacks on healthcare through YouTube, Twitter, Facebook and other social media. Syrian diaspora groups have organized to provide humanitarian aid, training for physicians and funding. Local NGOs document violations. All liaise with US, European and regional organizations, as well as international and local authorities.

Civil society has mobilized on the global level through the complementary Healthcare in Danger Project and the Safeguarding Health in Conflict Coalition, the latter composed of health provider, human rights, health professional and academic members and observers.

\section{Conclusion}

The problem of attacks on and interference with health workers, facilities, ambulances and persons seeking care is complex, and attention is long overdue. The problem is not insoluble and indeed there is reason for optimism. Bellagio conference participants are convinced that greater and more considered attention to the issue as a fundamental aspect of human security can bring significantly more protection and respect for health than exists now. One participant, Margaret Mungherera, President of the World Medical Association, said that beyond the substance of our recommendations, the participants wished to convey a spirit of commitment and high aspirations that the work needed can be accomplished. Vision, commitment, pragmatism, research, a full toolbox of monitoring, reporting and accountability, and political will can get the job done.

\section{Acknowledgements}

The Center for Public Health and Human Rights is grateful to the Rockefeller Foundation for financial support for the Bellagio meeting. Additional funding was provided by the John D. and Catherine T. MacArthur Foundation. 
Special thanks to the meeting participants for their invaluable contributions, before, during and after the Bellagio meeting.

For more information, visit: www.jhsph.edu/ humanrights.

Copyright $\odot$ Center for Public Health and Human Rights, Johns Hopkins Bloomberg School of Public Health.

\section{Call to action}

International humanitarian and human rights law recognizes the obligation and/or the responsibility of governments and non-state actors to respect and protect health workers, facilities, medical transports and the people they serve. Violations undermine the human security and health of conflict-affected populations, disrupt health systems and undermine equitable access to healthcare, resulting in avoidable loss of life and human suffering. We, the assembled, believe urgent action is needed to address the problem and call upon the international community to advance the security of health, particularly in situations of armed conflict and internal disturbances, through the following actions:

1. States and armed groups. At all times, including during armed conflicts and internal disturbances, respect healthcare workers, facilities, transports and services, and persons seeking care, by not attacking, interfering with, threatening or obstructing them; refrain from punishing health workers for providing treatment to individuals in need of medical care on account of the patient's ethnic, religious, national, political or military affiliation or other non-medical considerations; and ensure availability of safe and secure access to and equitable distribution of quality healthcare.

2. States. Train their military, police forces and other law enforcement agents to adhere to legal standards and assure protection of health services, health workers and people seeking care; armed groups - similarly raise awareness among their forces to comply with their international obligations to respect healthcare workers, facilities, transport and services, and persons seeking care.

3. States, with the support of the UN. Take action to stop attacks and hold perpetrators to account in national and, where appropriate, international courts and/or special tribunals.

4. States. Make explicit in national law the respect for and protection of the delivery of healthcare and health workers in times of armed conflict and internal disturbances, and reaffirm and reinforce these norms through the UN General Assembly, the Security Council and the Human Rights Council.

5. States. Through ministries of health and other relevant agencies and UN bodies, establish, strengthen and provide resources for systematic monitoring and reporting of attacks on health workers, facilities and transports, and individuals seeking care, and support the implementation of ongoing initiatives by the UN Special Representative for Children and Armed Conflict and the WHO designed to collect and disseminate data on attacks on health services and encourage field-based reporting by the High Commissioner for Human Rights.

6. States, through the UN. Engage in processes such as Universal Periodic Review, treaty body review and mechanisms for the protection of civilians and children affected by conflict to promote compliance with international law and accountability for perpetrators.

7. States, relevant UNentities, NGOs, and professional health organizations and ministries of health. Promote, disseminate and implement recommendations 
of the International Committee of the Red Cross Healthcare in Danger project to increase security of healthcare services and health workers in the field.

8. Health professional organizations. At the national and global level promote universally accepted standards of professional conduct among health workers in armed conflict and internal disturbances, including training health workers on human rights and medical ethics and advocating for protection and security of health services and health workers.

9. States, the WHO and the Global Health Workforce Alliance. As part of the UN post-2015 development agenda process incorporate strategies to address the problem of interference with healthcare and address attacks on health workers in the human resources for health agenda and related initiatives.

10. Civil society actors. Actively engage states and relevant international organizations to advance protection of healthcare in armed conflict and internal disturbances.

11. States and donors. Support civil society engagement through capacity building, technical assistance and funding.

12. States and other research funding bodies sponsors, and researchers and practitioners. Conduct in-depth studies on the nature of violations and the perpetrators, as well as the consequences of lack of protection of healthcare functions on the health and development of the population.

\footnotetext{
Agenda for research as foundation for protection of health workers, patients and facilities in times of violence
}

\section{Understanding and acceptance of norms of respect and protection for health services in times of violence:}

a. What is the level of knowledge of norms across stakeholders?

b. How do laws designed to protect state security affect norms regarding respect for health professional impartiality and autonomy?

\section{Understanding the impact of attacks and threats on health systems:}

a. What is the impact of violence in the short, medium, long term, inflicted on: Health workers, including effects on retention and migration?

Health infrastructure, including hospitals and transportation?

Health delivery, including access to and availability of essential medicines?

Public health programming and disease prevention?

Health outcomes?

b. What coping mechanisms have health workers and those in need of care developed to maintain secure access to healthcare in conflict?

\section{Understanding forms of and motiva-} tions for conflict-related violence toward healthcare:

a. What motivates attacks in varying contexts?

b. Can patterns in attacks be identified?

c. Can a taxonomy of attacks be developed?

\section{Informing protection strategies:}

a. What strategies to prevent or stop attacks, or limit their impact, have worked, in which contexts, and why?

b. How can lessons learned be best translated into practice and empower local healthcare providers working in conflict? 